\title{
The Freedom to Teach Using open educational resources in your courses.
}

Claudia Holland, Karyn Pallay, Jane Rosecrans \& loulia Rytikova 
"...teaching, learning, and research resources that reside in the public domain or have been released under an intellectual property license that permits their free use and re-purposing by others. OER include full courses, course materials, modules, textbooks, streaming videos, tests, software, and any other tools, materials, or techniques used to support access to knowledge." 


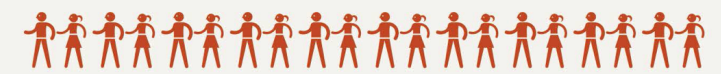

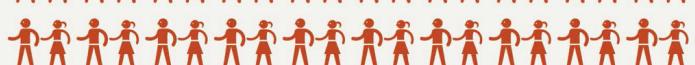
等,

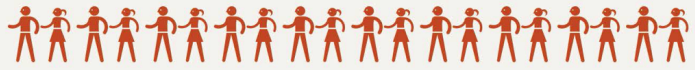

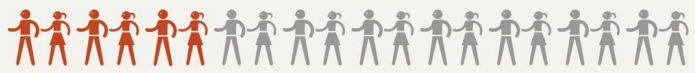

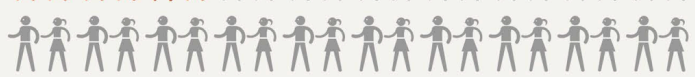

$65 \%$ do not purchase textbooks at some point due to cost

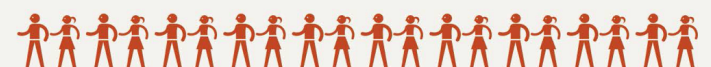
$35 \%$ take fewer courses

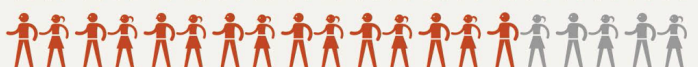
due to textbook cost

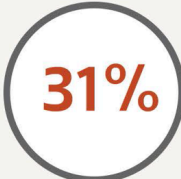

choose not to register for a course due to textbook cost

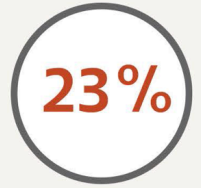

regularly go without textbooks due to cost

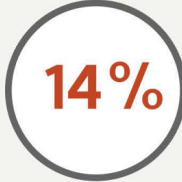

have dropped a course due to textbook cost

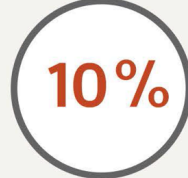

have withdrawn from a course due to textbook cost 


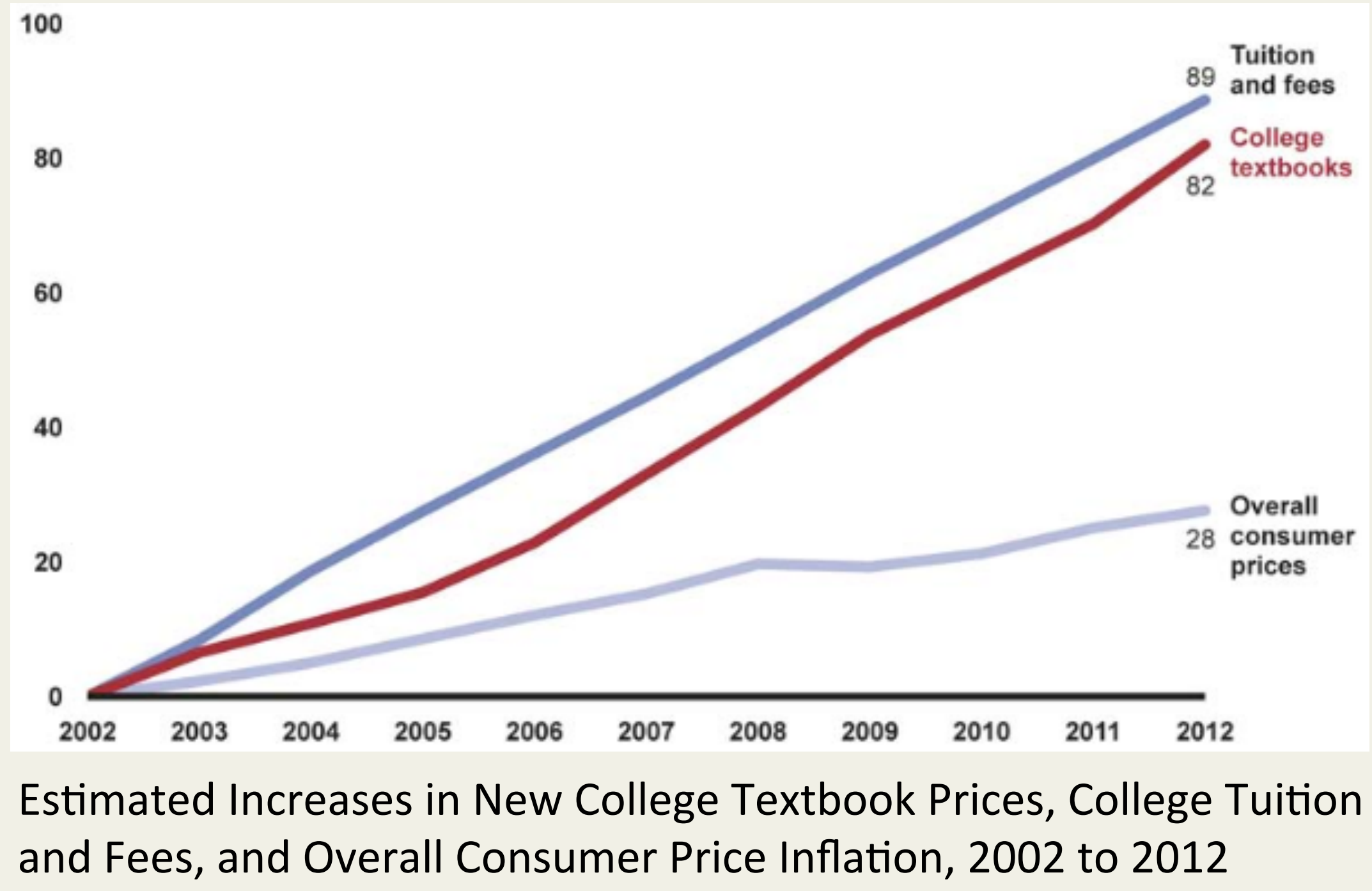


Consumer price indexes for tuition and school-related items, not seasonally adjusted, January 2006-July 2016

January $2006=100$

- All items - College tuition and fees

- Elementary and high school tuition and fees

- Childcare and nursery school

- Technical and business school tuition and fees

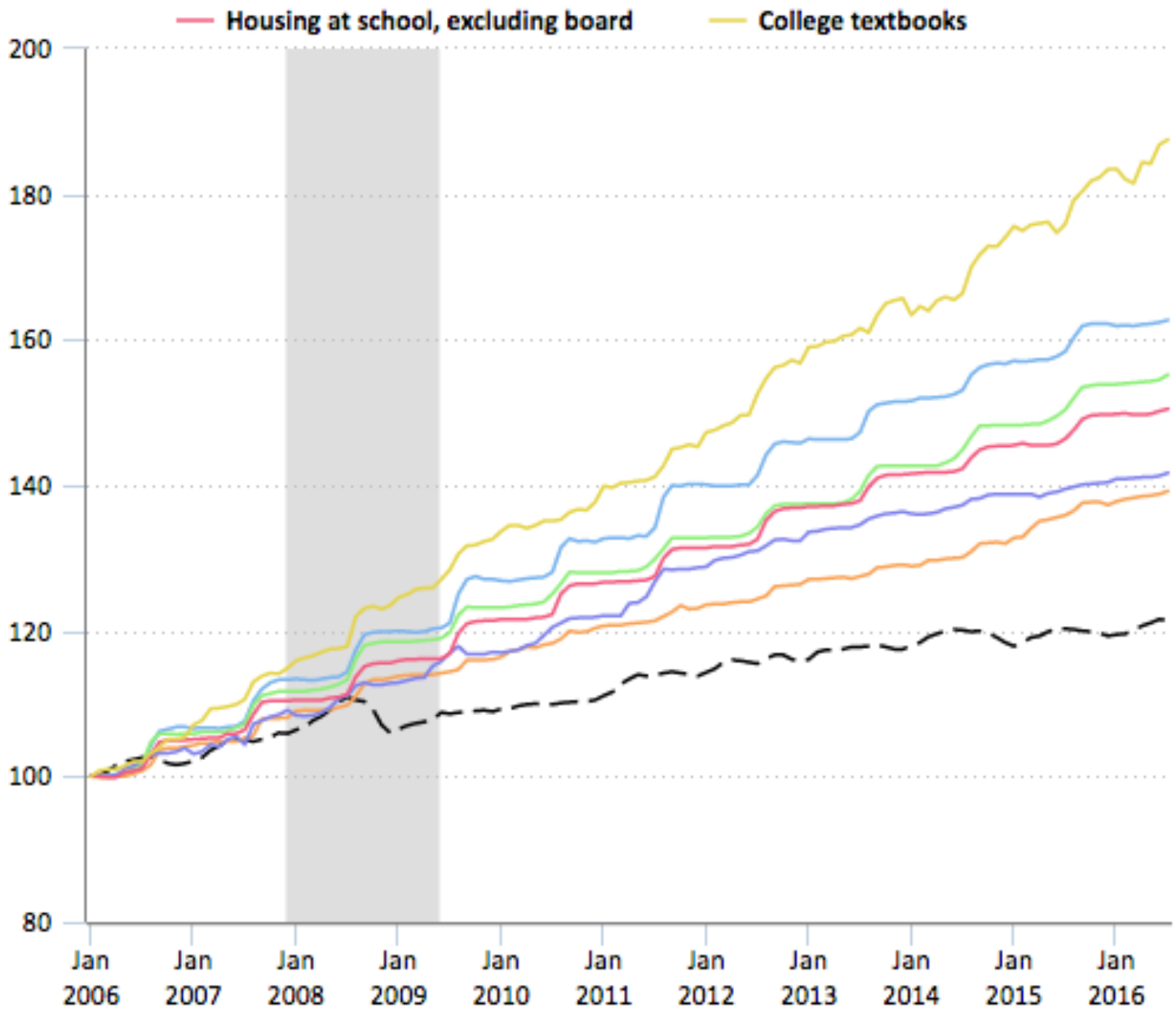

Click legend items to change data display. Hover over chart to view data.

Shaded area represents recession, as determined by the National Bureau of Economic Research.

Source: U.S. Bureau of Labor Statistics. 


\section{Preliminary OER research indicates. . .}

- Gen ed textbook costs average $\$ 90.00 / b k$

- Total cost of textbooks may exceed total tuition cost

- Students may be forced to choose between buying textbooks and taking fewer classes

- The use of OER has not negatively impacted student learning

- Free textbooks reduce barriers to academic success 


\section{Why are you interested in exploring open educational resources?}




\section{Free textbook impact on Mason students}

One free textbook for each 22,304 degree-seeking undergraduate (Fall 2015)

Savings $=\sim \$ 2,007,360$ 


\section{Creative Commons Licenses}

- Six choices available https://creativecommons.org/licenses/

- Assigning a license does not supersede your copyright unless you choose a CCO option.

- Attribution required of all CC options (built into license), except CCO. 


\section{The 5Rs}

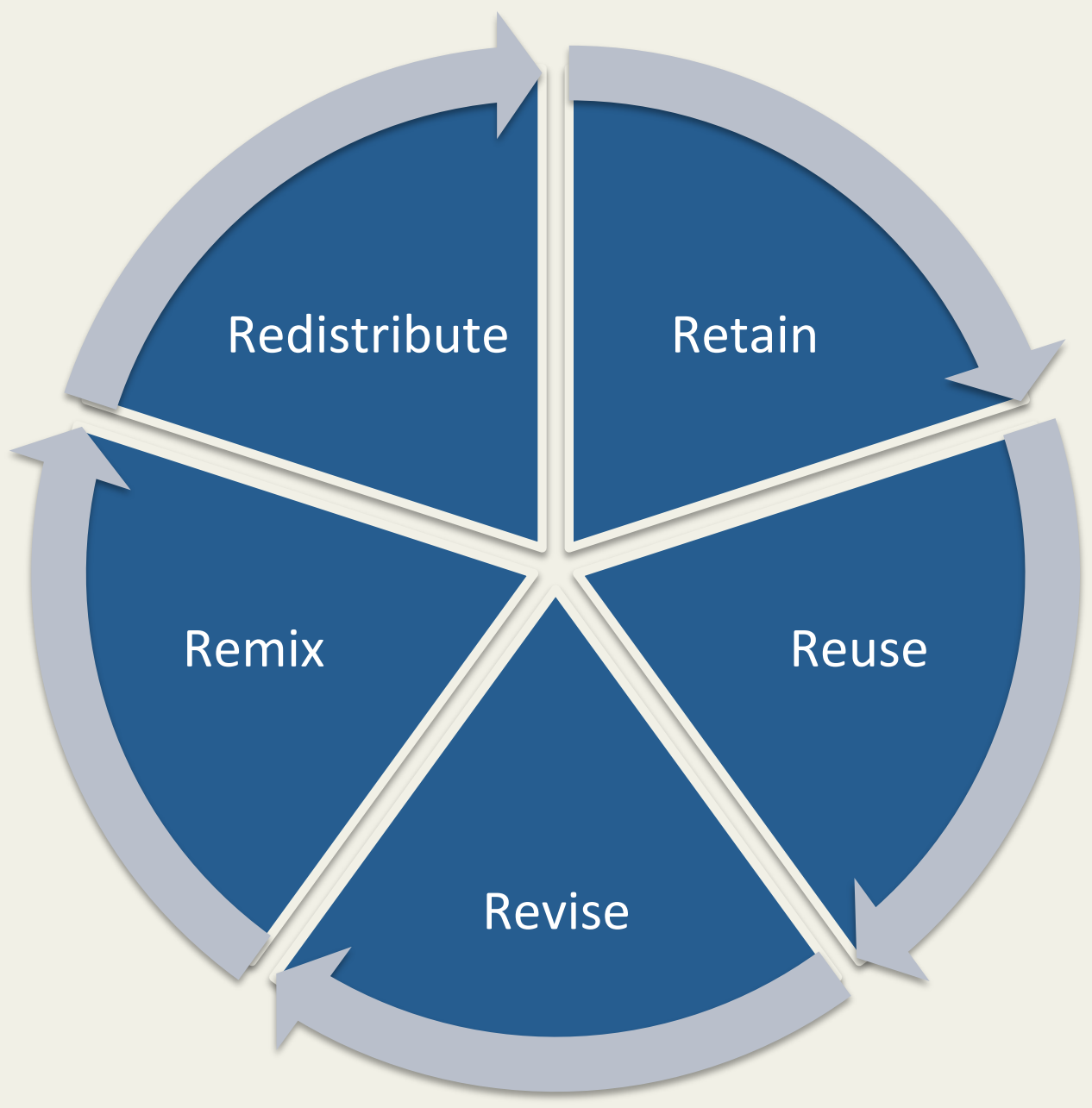




\section{Technical Framework for Open Content}

- Access to editing tools

- Level of expertise required

- Meaningfully editable

- Self-sourced 


\section{Current barriers to OER adoption}

- Limited (but growing) pool of high-quality materials

- Little knowledge about what's available

- Few resources at the campus level for faculty who want to adopt/adapt open materials

- Limited or no state and national legislative investment to spur innovation 

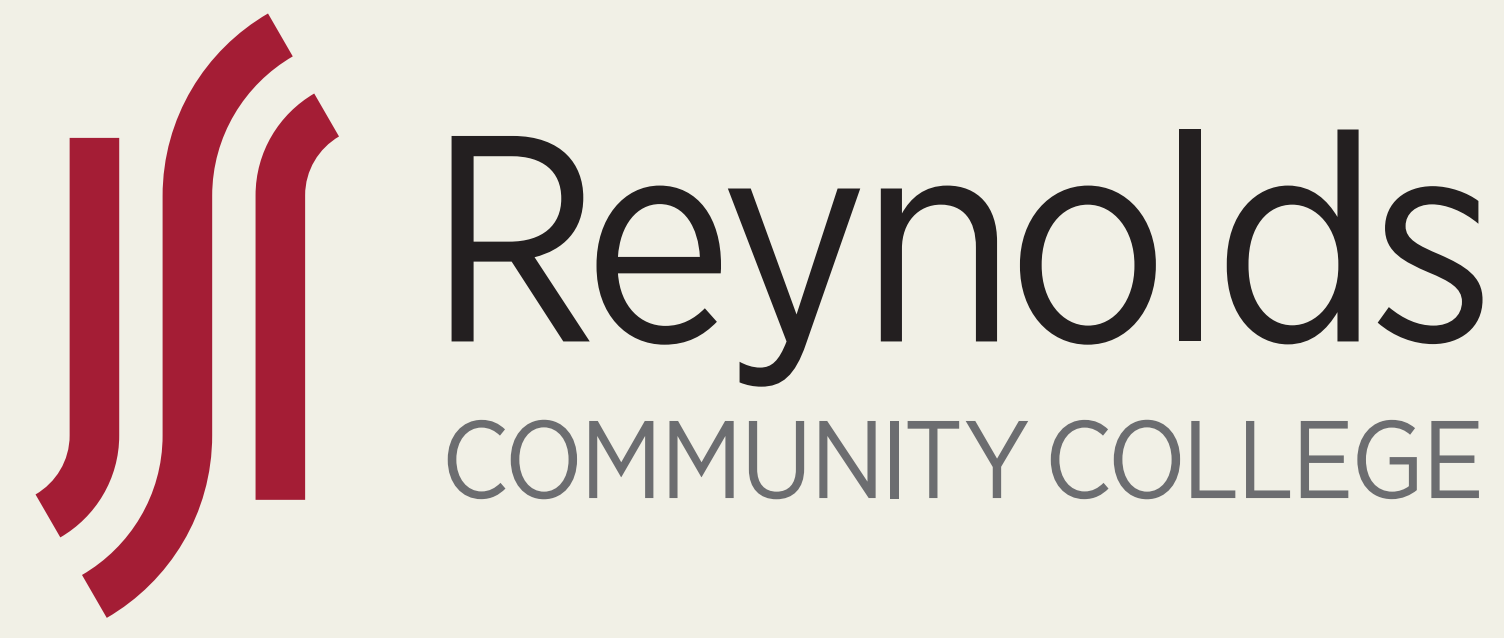

https://signin.my.vccs.edu/cas/login?service=https\%3A\%2F\%2Fportal5.my.vccs.edu\%2Fc\%2Fportal\%2Flogin 


\section{Looking for content}

- See the resources at http://publishing.gmu.edu/communication/openeducational-resources/

- Find materials in the public domain via http://openculture.com http://gutenberg.org https://archive.org/details/texts http://search.creativecommons.org 


\section{Licensed content via George Mason University Libraries}

- Databases by subject or title http://infowiz.gmu.edu/dbs/subjects/ index.php

- eBooks http://infoguides.gmu.edu/ebooks

- Videos http://infoguides.gmu.edu/mediaservices 

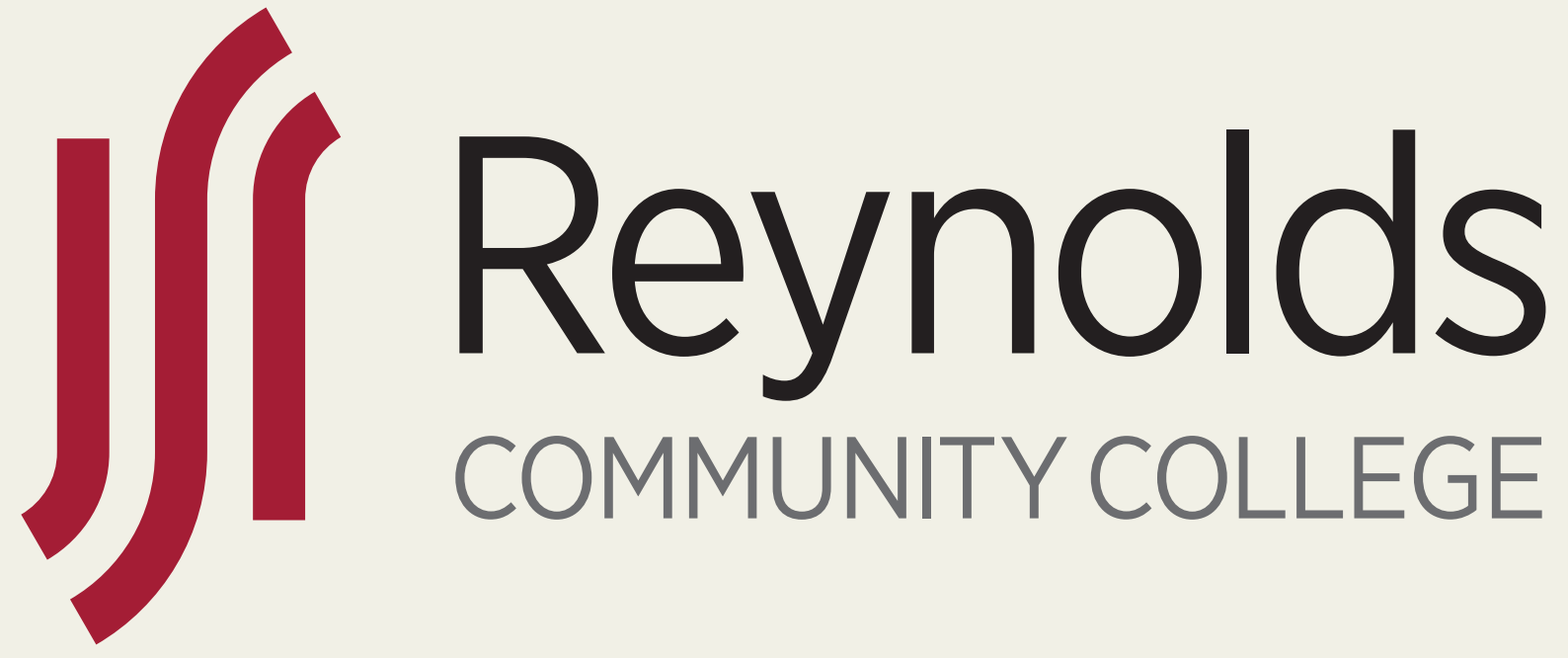

http://eng112oer.weebly.com/ 


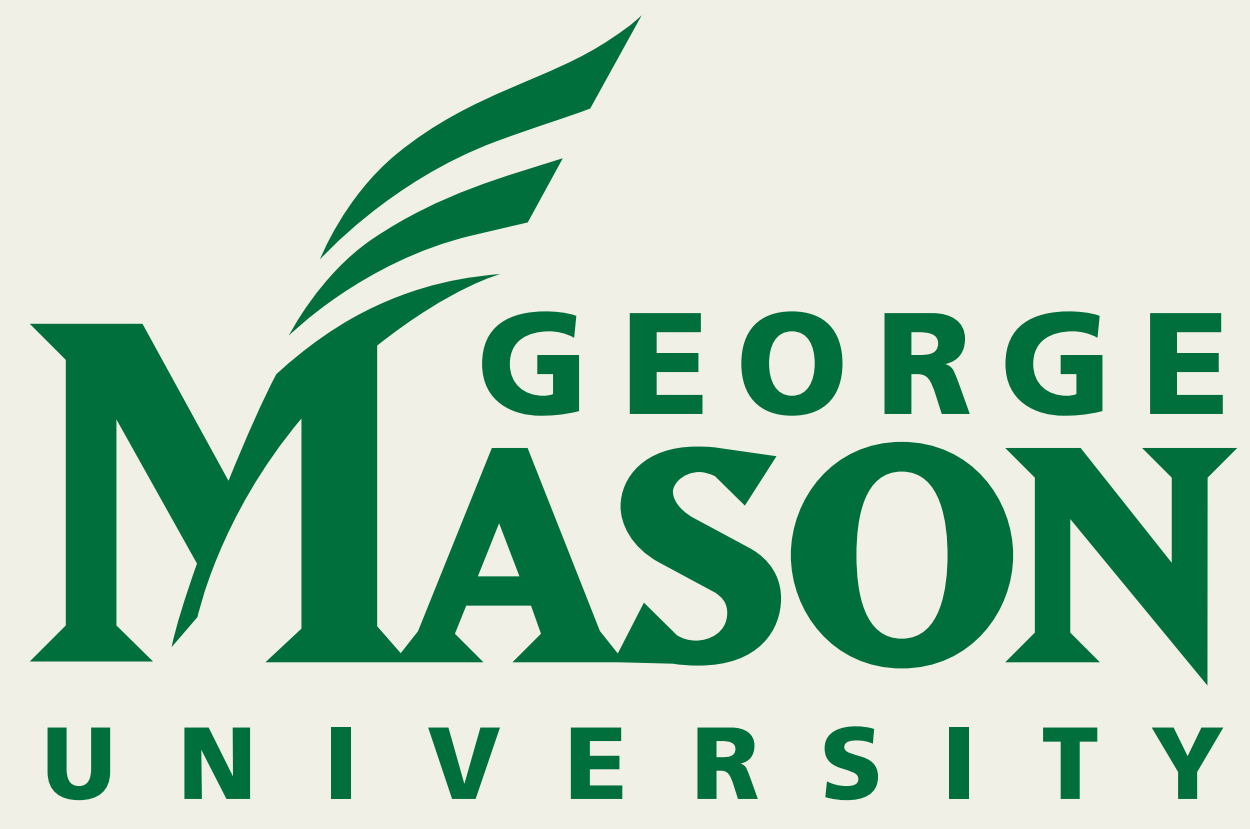




\section{Department of IST}

Information Sciences and Technology (IST) department in Volgenau School of Engineering:

- Undergraduate, Graduate, PhD programs

- Over 1,500 students

- About $70 \%$ of students transfer from community colleges

- Most IST students pay for their education themselves

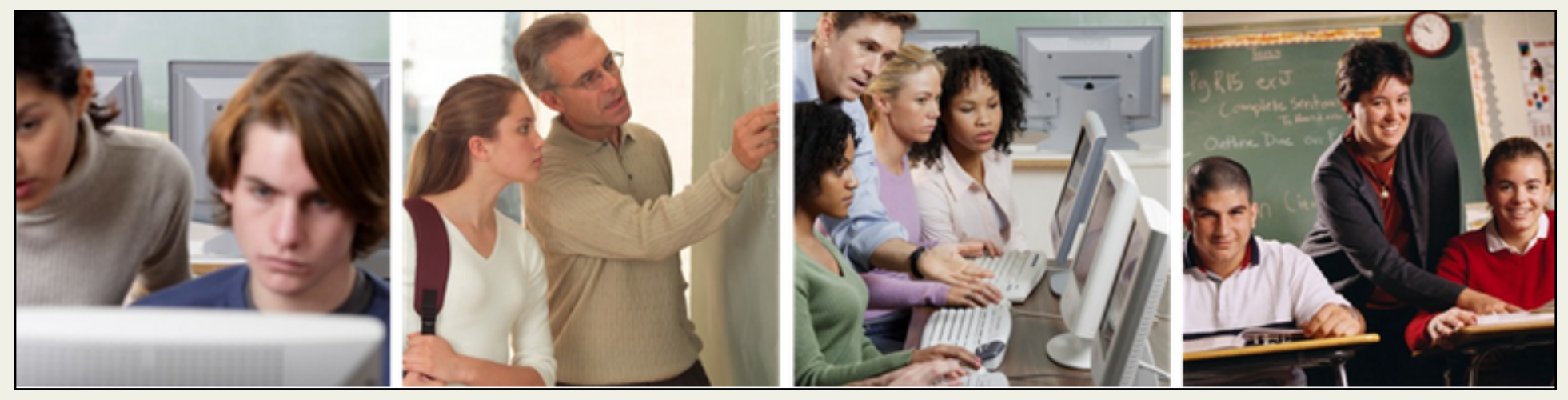




\section{Personalized Learning}

Personalized learning and mentoring is often viewed as one the most effective methods in student learning, helping not only a less proficient student significantly improve and cover his/her gaps, but also a talented student further immerse in advanced academic topics. 


\section{Source of Inspiration}

- Eight undergraduate and graduate courses

- Over 800 students per year

- Approximately 10 full-time and adjunct professors

- About 10 teaching assistants

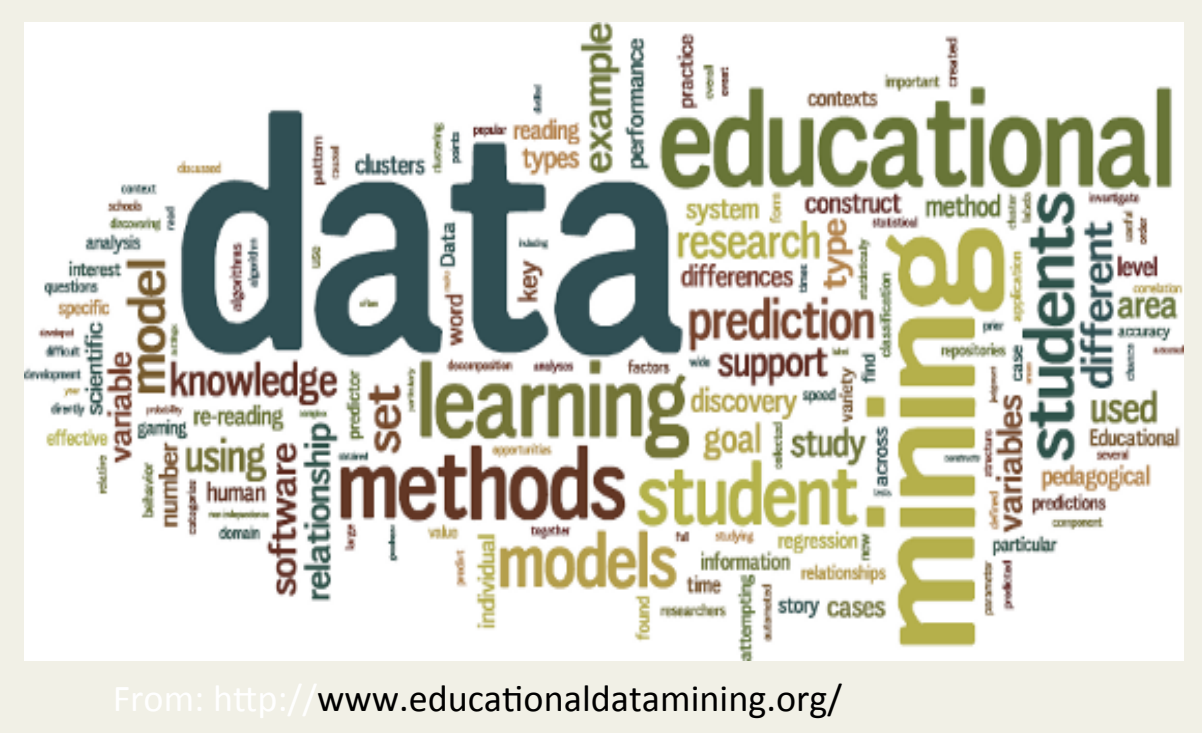




\section{OER at IST: Pros}

Two graduate courses on Big Data Analytics

(2014 - 2016):

- Perfect fit due to the nature of the courses

- Improved knowledge synthesis skills

- Higher level of personalization

- Customized course completion

- Increased course adaptability 


\section{OER at IST: Cons (cont.)}

Two graduate courses on Big Data Analytics

(2014 - 2016):

- Increased course development time

- Temporary nature of some resources

- Inconsistency in OER learning resources

- Sense of an overwhelming amount of materials to study 


\section{Next Challenge}

Incorporating OER to support undergraduate research 


\section{Mason's 4-VA OER pilot}

- 11 projects

- 37 faculty involved

- Awards $\$ 2,000$ to

$\$ 8,000$

- 11 individual courses

- 3 programs or large enrollment courses $\diamond$ Initial investment $\sim \$ 45,000$

$\diamond$ Potential student savings -

$$
\sim \$ 1,370,000
$$




\section{A strategy for getting started. . .}

1) Decide whether you want to look for open content used by others in your discipline? Use an existing open textbook? Or create your own materials?

2) Contact your subject librarian for assistance with finding open content that meets the 5Rs. Don't forget, subscription material is "free" to your instructors and students.

3) Find content that supports your pedagogy \& student learning outcomes. Work with an Instructional Designer, if needed, to align them.

4) Identify a rubric to use when reviewing quality (e.g., http://open.umn.edu/opentextbooks/ReviewRubric.aspx). 


\section{Strategy (cont'd)}

5) Edit materials, as needed. Seek technical help when there are obstacles.

6) Address student accessibility at the outset. Your institution's Accessibility office will assist, if needed.

7) Deliver your content via any LMS platform (Mason uses Blackboard) or website.

8) Create open content assessment forms for your students to complete at the conclusion of a course.

9) Build in time to update or tweak content annually.

10) SHARE!! Use the OER Commons and your institutional repository (e.g., MARS) to preserve your content and make it available to others. 


\section{Sources}

Slide 2: William and Flora Hewlett Foundation. (2013). Open educational resources. http://www.hewlett.org/programs/education-program/open-educational-resources

Slide 3: Florida Virtual Campus. (2012). 2012 Florida Student Textbook Survey. Tallahassee, FL. http://www.openaccesstextbooks.org/\%5Cpdf\%5C2012 Florida Student Textbook Survey.pdf

Slide 4: U. S. Government Accountability Office, Report to Congressional Committees (2013, June). College Textbooks: Students have greater access to textbook information. Report No. GAO-13-368. http://www.gao.gov/assets/660/655066.pdf

Slide 5: Bureau of Labor Statistics, U.S. Department of Labor, The Economics Daily, College tuition and fees increase 63 percent since January 2006 on the Internet at

http://www.bls.gov/opub/ted/2016/college-tuition-and-fees-increase-63-percent-sincejanuary-2006.htm.

Slide 6: Fischer, L., Hilton, J., Robinson, T.J. et al. A multi-institutional study of the impact of open textbook adoption on the learning outcomes of post-secondary students. J Comput High Educ (2015) 27: 159. doi:10.1007/s12528-015-9101-x.

Hilton, J. Open educational resources and college textbook choices: a review of research on efficacy and perceptions. Education Tech Research Dev (2016) 64: 573. doi:10.1007/s11423-016-9434-9.

Slide 10: Wiley, D. Defining the "Open" in Open Content and Open Educational Resources. [Blog post, n.d.] http://opencontent.org/definition. This material was created by David Wiley and published freely under a Creative Commons Attribution 4.0 license at http://opencontent.org/definition/.

Slide 11: Wiley, D. Poor Technical Choices Make Open Content Less Open. [Blog post, n.d.] http://opencontent.org/definition. This material was created by David Wiley and published freely under a Creative Commons Attribution 4.0 license at http://opencontent.org/definition/.

Slide 12: Center for Public Interest Research, Inc., Student PIRGs (2014). Fixing the broken textbook market: how students respond to high textbook costs and demand alternatives.

http://uspirg.org/sites/pirg/files/reports/NATIONAL\%20Fixing\%20Broken\%20Textbooks \%20Report1.pdf. 